\title{
Developmental experiences related to retirement from sport: insights from Japan
}

Miyako Oulevey

Daisuke Hirata

David Lavallee

Naohiko Kohtake

This is an Accepted Manuscript version of the following article, accepted for publication in Journal of Loss and Trauma.

Oulevey, M., Hirata, D., Lavallee, D. \& Kohtake, N. (2020) 'Developmental experiences related to retirement from sport: insights from Japan'. Journal of Loss and Trauma. DOI:

https://doi.org/10.1080/15325024.2020.1852825

It is deposited under the terms of the Creative Commons Attribution-NonCommercial License (http:// creativecommons.org/licenses/by-nc/4.0/), which permits non-commercial re-use, distribution, and reproduction in any medium, provided the original work is properly cited. 
Miyako Oulevey

Keio University, Japan

Daisuke Hirata

Keio University, Japan

David Lavallee

Abertay University, UK

Naohiko Kohtake

Keio University, Japan

16

17

Miyako Oulevey is a PhD student in the Graduate School of System Design and

Management at Keio University, Japan.

19

Daisuke Hirata, MS, is a researcher in the System Design and Management Research

20 Institute at Keio University, Japan.

21

David Lavallee, $\mathrm{PhD}$, is a professor in the School of Applied Sciences at Abertay

22 University, UK.

Naohiko Kohtake, PhD, is a professor in the Graduate School of System Design and

24 Management at Keio University, Japan. 
Abstract

27 Psychological support systems for retiring elite athletes can assist them in making career

28 transitions out of sport. The purpose of this study is to further advance research in this area,

29 with a specific focus the developmental experiences related to the sport career transition

30 process in Japan. One retired Olympic medalist was analyzed with a life story analysis

31 method. The findings highlight the psychological difficulties experienced by retiring athletes and the system requirements to help them make an optimal transition.

33

34

35

36

37

38

39 Keywords: career transition, athletic identity, elite athlete

40

41

42

43

44

45

46

47

48

49 
for most sport organizations is to optimize performance, so the system tends to neglect what happens to athletes when they retire (Lavallee, Park, \& Taylor, 2014). This lack of support has the potential to lead to a range of adjustment difficulties for retiring athletes, including psychological adjustment. percentage of athletes experience psychological adjustment difficulties following retirement from sport. The study found that across 126 published studies and 13,511 participants, $16 \%$ $(1,768)$ athletes reported career transition difficulties. Park et al. also observed that most studies (i.e., 68\%) have reported that their participants expressed negative emotions, feelings of loss, identity crises, and distress when they ended their career. The experience of loss, in particular, has been a focus for sport career transition practitioners and researchers (Lavallee et al., 2014).

Lavallee et al. (2012) have outlined a conceptual model of retirement from sport in an effort to gain a better understanding of the career termination process. In the model, psychological adjustment to athletic retirement is influenced by three interrelated factors. The first involves the causes of career termination, with a focus on voluntary and involuntary reasons for retirement. The second factor considers available coping resources for adaptation to career transition, including social support. The third factor in the model involves developmental experiences related to the adaptation process, focusing specifically on identity-related issues. As Lavallee et al. suggest, the conceptual model can assist organizations in developing effective support system as once specific retirement difficulties are demonstrated, appropriate psychological support can be recommended. At the present 
time, however, there has been very little research conducted on the needs of retiring athletes and the system requirements to help them make an optimal transition.

In Japan, several studies have been conducted on the retirement experiences of elite athletes. Toyoda and Nakagomi (1996) found out that Japanese athletes faced some psychological difficulties following sport career termination. Nakagomi (2012) highlighted the risks associated with a strong and exclusive athletic identity for retiring Japanese athletes. A career assistance program, the Japan Career Academy (JCA), was started in 2008 to support Japanese Olympic athletes at retirement. Hong and Coffee (2018) recently investigated the features of the JCA and identified that, although it had strong occupational support provision, psychological supports for retiring athletes were not provided due to a lack of qualified practitioners.

Two recent studies in Japan by Oulevey and colleagues (Oulevey, Tsutsui, \& Kohtake, 2018; Oulevey, Lavallee, \& Kohtake, 2020) have advanced research in the area through the testing of two of the three factors outlined in Lavallee et al.'s (2012) conceptual model of retirement from sport. Oulevey et al. (2018) surveyed 472 retired Japanese athletes who competed in either the Summer or Winter Olympics and found that individuals who retired voluntarily and experienced greater control over their reason to retire required less psychological adjustment than those who didn't. Some gender differences were identified in the research, with female athletes who competed in the Summer Olympics tending to require greater psychological adjustment. Oulevey et al.'s (2020) study extended this finding by assessing the different types of coping strategies needed by 44 Japanese female athletes who made a career transition out of elite sport. This research found that psychological stress accounted for $69 \%$ of all retirement-related coping needs.

The purpose of the present study is to further advance research in the area of retirement from sport, with a specific focus the developmental experiences related to the sport 
career transition process in Japan. A life story analysis method (Sakurai, 2002) was adopted

101 in order to examine the third and final factor in Lavallee et al.'s (2012) conceptual model,

102 including identity-related issues. The study aimed to advance knowledge in relation to

103 psychological support systems for retiring elite athletes.

Method

105 The Participant

One Olympic medalist (hereinafter referred to as "P") in synchronized swimming

107 (hereinafter referred to as "Synchro") was interviewed. She was initially approached by the

108 first author to participate in this study because she was a retired Olympic athlete. After

109 explaining the purpose of the study and her broadly outlining her developmental experiences

110 related to her career transition process as an elite athlete, we felt P's retirement story would

111 help us achieve the study aim.

112 Procedure

A life story interview was conducted in a room of P's home. All data obtained from

114 the one-on-one interview were tape-transcribed. A semi-structured interview guide was

115 developed to ensure the freedom to change the expression and order of the questions

116 according to the situation. The question items were designed based on the Athletic Retirement

117 Survey (Alfermann et al., 2004).

118 Informed Consent

119 The purpose of the research and audio recording of the interview was explained to the

120 participant prior to data collection, and consent was obtained. During the interview, the

121 highest priority was given to respect human rights and ensure safety, such as guaranteeing the

122 right to choose to stop participating in the research at P's own will. The participant was asked

123 to confirm the content of the transcribed interview prior to data analysis. All verbatim quotes 
124 included in this paper were also confirmed by P. This research was approved by the research

125 ethics screening of the university to which the first author belongs.

126 Credibility

127 The main analyst (first author) is an expert in sport psychology and has over 20-years

128 experience of research and practice in athletic retirement. This background allowed the

129 research to be distinguished from other media interviews. An independent researcher

130 confirmed the analysis process to verify if the first author's analysis was conducted from a

131 consistent point of view. When different interpretations occurred, discussions were held until

132 the opinions of both parties agreed to ensure certainty (Miles \& Huberman, 1994; Sakurai,

133 2002). The independent researcher is an expert in sport psychology and has experience in

134 qualitative research. During the interview, the interviewer (first author) asked questions in a

135 non-directive manner so as not to induce the participant to speak. To secure credibility, the

136 participant's own words were used in the analysis by considering the influence of the

137 interviewer. However, a study limitation is that interview responses were originally

138 transcribed in Japanese, and quotes were then translated into English.

140 P started participating in the sport of Synchro at the age of 6 and was influenced by

141 her two sisters, who were already participating in Synchro. P participated in the Olympics at

142 the age of 20 and won two medals. At the age of 23, P retired and experienced various careers

143 such as going on to complete a master's degree at university, getting married and childbirth,

144 and becoming a TV commentator. The present life story study identified 9 themes, including:

145 1) Starting synchro; 2) Deepening commitment; 3) Competitive characteristics; 4) Sporting

146 values; 5) Retirement difficulties; 6) Current challenges; 7) New values; 8) Transferable

147 skills; and 9) Advice for the next generation.

$148 \quad$ Starting Synchro 
"I started Synchro at the age of 6 in the 1st grade of elementary school, or 7 years old. Then it was actually our three sisters. I am the youngest of the three sisters and my two sisters happened to go to a Synchro course there, and two sisters got in there. Well, my mom is a strange person, she thinks it's better doing something not everyone does than doing something everyone does, like swimming. Yes, then two older sisters did Synchro, and I'm a 5 year apart from my second sister. I started naturally looking at them."

P's reason why she started Synchro was not a self-motivated intention to do it. As the

can be said that the beginning of the relationship with Synchro for P was due to an extrinsic motivation. This type of motivation can be explained with self-determination theory of motivation (Deci \& Ryan, 1985). Her initial motivation was an extrinsic motivation with her family involvement as a social support.

\section{Deepening Commitment}

"There was one time I really wanted to quit at the beginning. It was when I moved from 6th grade to junior high school....It was a bit tough in the days when I didn't swim for 2 weeks. The fact that "a person who doesn't swim”. So, I thought going back. All came to me, so I went back. At that time, I realized that I can't continue unless the coach believes me. I'm really a false accusation. I don't remember doing that, but the coach said I did. No matter how much I love Synchro, I can't continue unless she believes me. So, I quit. But I loved Synchro so I went back. When I couldn't swim for two weeks, I realized that I really needed Synchro. I was really worried. I was in the middle of my adolescence. You know it was a tough time. The environment changed. Started going to a junior high school. In many ways, I felt that it was painful that I could not do Synchro. Yes, no matter what I did, it wasn't fun. Even when running in the track and field club. It was when I started the first grade in the junior high school. Then, I went back, well it was really fun."

$\mathrm{P}$ felt that she was not trusted by the coach so that decided to quit Synchro. While P

was away from Synchro, she got involved in the track and field club for two weeks. This

showed how important the trusting relationship with the coach was to P for continuing

Synchro. However, for the two weeks away from Synchro, P felt that it was difficult to see herself without Synchro. P realized that she really liked and needed Synchro. The commitment to immerse herself in Synchro was growing, and at the same time, it is considered that her motivation was changed. This motivation shift can be explained with the self-determination continuum (Ryan \& Deci, 2000). Her motivation was shifted to integrated 
regulation (she needed Synchro), then to intrinsic regulation (enjoying Synchro). Her athletic identity as a synchro swimmer began to be built around this period.

\section{Competitive Characteristics} couldn't talk properly when her opinions differed from the coach's opinion. However, P still felt even now that she couldn't help acting like this. It is assumed that the expression "There was only zero or 100 at that time, don't you think?" is the feeling of asking the interviewer to understand. This kind of narrative with the generalization, "don't you think so?", can be considered that $\mathrm{P}$ recognized the interviewer understood the model story, which was observed as being referred to the "model story of an athlete who lives in the Synchro world."

Moreover, the expression, "zero or 100", can be regarded as a sense of distance from commitment. This way of thinking can be read as "all-or-nothing thinking" in cognitive therapy (Beck, 1995) and, as such, can cause stress in life events such as at retirement. "Well, how do I say, you know, maybe it sounds bad, but I'm, as an athlete, I really felt like a machine. I am like a Swimming Machine. I was treated as a Swimming Machine. The machine is named "Athlete". I was so sad that my opinion as a person was not respected or heard at all. To some extent, I thought I had been recognized as an athlete after overcoming both the Olympics and the World Championships. It is like a complete rejection."

The "swimming machine" is a metaphorical expression in that it does not move at her

209 Synchro. Synchro is a closed-skill sport. It is important to complete the prescribed

210 movements as practiced and to synchronize with others. It is very different from open-skill

211 sport, such as soccer and basketball, where the situation changes on the spot and it is

212 necessary to judge accordingly. Also, because of the characteristic of the sport being scored 
213 by others, it can be summarized that the coach's evaluation becomes absolute, leading to the

214 expression that the athlete is a swimming machine driven by the coach. For $\mathrm{P}$, it seems that

215 she started wanting to assert her opinions since she had achieved some results; however, the

216 reality was different. Because she expected that her opinion could be listened by the coach, $\mathrm{P}$

217 was sad and ended up saying "I am like a Swimming Machine". At the same time, it can be

218 said that a machine is highly accurate and will never betray control. The expression might be

219 capturing herself as a synchronized swimmer who established a strong connection with the coach who was the pilot of the machine. The phrase "swimming machine" can be said to be a characteristic expression of athletic identity in terms of how she perceived herself. It is also assumed that thinking herself as a machine can be explained as a foreclosed athletic identity which often occurs among elite athletes and can lead to psychological adjustment difficulties (Brewer, et al, 1993, Lavallee \& Anderson, 2000).

"Even though I thought I did very well, the coach got mad at me. The score does not match. What is it? Sometimes when I didn't do well, the score was high. The coach praised me. That is, the thing I do and the result don't match. It is such a disgusting sport. At that time, I was really wondering what this was about."

For example, in soccer, players can visually confirm the track of the ball kicked by the players. Even in gymnastics, a similar sport to Synchro as it is a scoring sport, it is possible to feel and visually check the quality of work by touching the ground. However, it can be assumed that it was a very difficult sport to check the performance by the Synchro swimmer, herself, as one's sense of performance and the evaluation of others may be different. Generally, in sport, the feeling of "I did it" is one of the great feelings; however, the feeling did not match the result nor coach's evaluation for $\mathrm{P}$. That fact influenced her view of it being "a disgusting sport". Based on the phrase "at that time", it is believed that P now accepts and understands the characteristics of Synchro. I did well. But you know, we are the people who are graded, so it's really important and sensitive about other's evaluation. I was just worried about what people thought about me." 
concerned about the evaluation of others because Synchro was a judging sport. Through

244 Synchro, a sport in which one's feelings and others' evaluations often differ, the meaning of

being oneself who cares about others' evaluations was captured. Nakagomi (2012) pointed

out that elite athletes who had a strong athletic identity in adolescence would have

psychological challenges at their retirement if they were not able to follow career choices

which their surroundings offered. If P's thought of "sensitive about other's evaluation" was

cultivated through Synchro, then it can be considered that this thought may negatively

influence here psychological adjustment to retirement.

"Perhaps until now, there were many people who taught me without me asking to teach. I was doing it even though I didn't like doing it. So, I think I didn't really ask for anything."

The days P devoted herself to Synchro were with the strict coach's guidance, which

meant that $\mathrm{P}$ was always with someone who taught her. There is also a competitive

characteristic in Synchro, where the evaluation by others was important. And since P's

training was usually for meeting the demands of coaches, $\mathrm{P}$ analyzed herself as having few

experiences in seeking teaching from herself. Through Synchro, P captured her own

tendencies of how she interacted with others.

$\underline{\text { Sporting Values }}$

"Well, I am very weak. My mind, kind of my mental, my mind is weak. I'm influenced easily and becomes lazy. Well, basically I just don't want to lose against myself."

Based on the self-awareness, it was shown that P valued "I wouldn't lose to myself".

It can be said that $\mathrm{P}$ was always living a life that was not easy. Perhaps $\mathrm{P}$ was able to move

toward autonomy because she could recognize herself as a person who wanted to enjoy

herself without being overconfident. 
routine training. Maybe you know right? You can't help thinking each minute. Not fun at all. So, I realized at the age of being in an elementary school, it is refreshing to go and do a hard practice."

P had the experience of "skipping the training" when she was young. And, at that

time, $\mathrm{P}$ felt that skipping training was neither uncomfortable nor enjoyable, so that by the time when P was in elementary school, she ended up having the notion that "it is refreshing to go and do a hard practice". It is assumed that the kind of notion led her commit to Synchro and developed her athletic identity. Unlike the fact that adults simply say, "Don't skip training", P realized it by herself based on her own emotional experiences. So that $\mathrm{P}$ was grown up to become a voluntarily training athlete. Moreover, the expression of "Maybe you know right?", can be explained that the reference to the "model story of a player who lives in "the Synchro world" was also observed here, and the interviewer was asked to understand. "I would think that there is no point unless you win. But not only winning. Winning is not enough. Winning with the coach's OK sign is important. So even when I win, if the coach doesn't look happy, of course I try to win though, but then I have no clue. In myself, sometimes I have the feeling that I swam very well. So, when my feeling and evaluation match, I have great feeling of achievement. But, somehow there are quite a few things that I do not feel clear in myself."

$\mathrm{P}$ believed that it would be meaningless if she didn't win. At the same time, it was important for P to win with the coach's "OK sign". This is considered to indicate again that it is unique sport in which athletes cannot check their performances. Therefore, $\mathrm{P}$ can achieve a sense of accomplishment only when three points were established; winning, the "OK sign" from her coach, and her own feelings. It is assumed that $\mathrm{P}$ was not only committing to Synchro but also to her coach. It can be assumed that it would be psychologically difficult for $\mathrm{P}$ if her decision of career termination and career choice after retirement were not accepted by her coach. The similar case was seen in the previous research. Relationship with surroundings after retirement is one of the stressors among female elite athletes, and "People around me dictate my future" was one of the stressors. (Oulevey et al., 2020). athletes, Cirque is 365days. They have a day off two times a week though. But within 
that, if you hit $30 \%$, it's good. But, for the Olympics, you see, it's different. It's only once in 4 years and it's only 5minutes or 3minutes that you really need to focus. Extremely. You know? That's different."

After retired from Synchro, P worked at Cirque du Soleil for few years and performed in their Las Vegas show as a professional (a salary paid) Synchro swimmer. Comparing to her experience as a show performer, P explained the difference between an Olympic Synchro athlete and a show performer. The Olympics is held only once every four years, but the Las Vegas show was held every day. P thought that she needed to focus extremely when she was an Olympic athlete.

"It's not being perfect. Rather, I always want to aim higher. I want to go higher. The desire to be strong is extremely high. The desire is really big."

The expression "I always want to aim higher " showed a strong desire to set endless goals and continue to pursue better things. This is thought to lead to the expression " The desire is really big".

"I have the personality to drive myself hard. I feel I have to. Otherwise I can't do anything. So, I need to put myself in a tough situation. Otherwise I can't start doing things. That's me."

$\mathrm{P}$ analyzed herself that she could not move forward unless she put herself in a tough

situation. In other words, it can be said that $\mathrm{P}$ was able to drive herself even in a tough

situation. Moreover, $\mathrm{P}$ was also able to see the tough situation as if she had created it. This

kind of a coping strategy, reappraisal (changing the way a situation is viewed), is used

frequently by elite athletes. (Uphill \& Jones, 2012). Because of this self-awareness, it seems

that $\mathrm{P}$ knew what to do when she was in a tough situation during her athletic career.

\section{$\underline{\text { Retirement Difficulties }}$}

"I had huge pride at the beginning after retired. You see, in the Synchro world, I was a top. I had strange pride of myself used to be a top in the Synchro world, so that I couldn't say I don't understand honestly when I don't understand. I entered the TV world at first. I could have asked to get taught if I don't understand. But I tried to fix it by myself. It was tough. It was really tough. Then, I can't show my weaknesses or can't show my weak points. I felt I was so alone. Long time. But, you see I have pride. So, the ideal in me is really high. In everything. Even as a TV reporter, TV commentator, in myself, my ideal image was so high. This is good though, but then after all, my ability is not good at all. The gap was tough at the first year. I was a TV 
commentator once a week. Every time on the way back home in the taxi, I got very depressed. Cried going home. Really. It was really tough."

$\mathrm{P}$ was very depressed every time after finishing her job, and it was really tough.

However, P was not able to cope with the feeling by asking for help. P had a self-image associated with being on the top in the world of Synchro. And the pride with her self-image prevented her from asking for help. $\mathrm{P}$ is thought to be categorized an athlete who has "the Olympic self-image" (Petitpas et al., 1992). Petitpas et al. (2000) pointed out that the athletes with the Olympic self-image may have developed a sense of entitlement, and this expression of entitlement may be covering up feelings of fear or insecurities about lacking the skills necessary to become an elite performer in another career. It is assumed that P's case is similar. It is also considered that P had an irrational belief, "Absolute must's and should's" in Rational Emotive Behavioral Therapy (REBT; Ellis \& MacLaren, 1998) such as "I should do well in other world than sports", "I should solve problems by myself", "I shouldn't get taught by others", and "I shouldn't show my weaknesses". Because of these irrational beliefs, P ended up deciding to act alone.

"After all, when I retired, I wonder why all people in the world aren't working so hard. Why these people, they are saying they can't they can't when they are not working hard enough. I really don't get it. So? Well, then you just do it. Why you don't? I was really wondering why."

The criteria and the definition of "working hard" would be different depending on each person and each situation. However, it is considered that her firm definition of "work hard" had been completed from the experience of spending time with her teammates who aimed to participate in the Olympics and won medals during her career as an athlete.

Therefore, it seems that $\mathrm{P}$ applied her own definition to all people immediately after retirement, and P evaluated people as "they are not doing their best" from the gap with her own definition. It suggests that $\mathrm{P}$ was confused and irritated by the gap. It can be said that people who interacted with $\mathrm{P}$ changed through the retirement, and $\mathrm{P}$ felt the difference in the 
common sense between in her community during her athletic career and in others. It would be

difficult for P to get a social support from others with her feeling above.

"How do I say, really, I have to control my energy low. I shouldn't show my feeling out. Have to live without letting out of my feelings. I have to be gray. Gray color. I have to act like this. You know even if I tell them, no one understands. That's it. Okay okay, maybe that's the way it is. That is to become an adult. Wow, what is it? Somehow, it seems that people have to walk with the same pace in the society. You have to adjust."

$\mathrm{P}$ uses the phrase "act". It seems that P felt the need to live in a "grey" (not black or white, but rather in the middle) self, which is different from her true self. However, P thought that her feelings were not understood by others, and convinced herself that it meant becoming an adult and she tried to keep pace with the people in the society. As P said, "even if I tell them, no one understands", it is thought that P felt meaningless to talk to someone about her feelings. This can be seen in elite athletes at their retirement. Petitpas and Champagne (2000) pointed out that many transitioning athletes believe that few people understand what they are going through. In that case, it would be difficult to get a social support even if it is there. $\mathrm{P}$ was uncomfortable with the difference in her life as an athlete and the life after retirement. However, $\mathrm{P}$ can also felt that it was unavoidable. From this, it can be seen that $\mathrm{P}$ thought that the world in which she lives changed due to the turning point of retirement. The ways of thinking such as "acting like a grey color", "controlling my energy low”, and "walking with the same pace" are thought to be her coping strategies to go through her transition.

"I want to be targeting higher. I have my ideal image higher. I was able to reach in the high level in Synchro, but as a TV commentator, well, suddenly, a person like a baby takes on an ideal image for a greater level. There is a dilemma. I was also irritated about the laziness of the people around me."

$\mathrm{P}$ was willing to aim higher in the new working environment after retirement.

However, it was difficult for A to put out her ability in the commentator job which has no experience at all, unlike Synchro which had a long experience until then. As a result, $\mathrm{P}$ suffered the difficulty not being able to do well in the work. When P was not satisfied with 
her own ability, she was also judging people around her as lazy. It is thought that $\mathrm{P}$ was not able to share her feelings of difficulties with people around her if she judged them as lazy. At

393 the same time, it is questioned what kind of feelings $P$ had inside of her in evaluation of

394 others being "lazy".

\section{Current Challenges}

"As a wife, mom, TV commentator, all are not the same. In the past, I thought I just do whatever I want to do, but now, well, there are so many things you can't do even if you want to. Sometimes I feel what? But kids come first. Family first. Balance around that, the balance for living. How to balance yourself around that so that nothing breaks."

P used to have the idea of always doing what she wanted to do. However, now, she has to fulfill multiple roles as a wife, mother, and commentator. So that she seems to have come to the idea that there were things that she could not do even if she wanted to do. It is probable that $\mathrm{P}$ was able to concentrate on the role of an athlete in her athletic life. However, in the current situation where multiple roles needed to be performed at the same time, it can be seen that she was facing the new challenge of worrying about balance in life. It is questioned though if $\mathrm{P}$ didn't have to balance her life roles in her athletic life. Petitpas et al., (1997) emphasized the importance of recognizing multiple life roles. During P's athletic life, she would have had many different life roles such as daughter, student, athlete, friend, etc., and she would have balanced the roles. However, P seems to have difficulties to balance multiple roles as a new challenge. Recognizing multiple roles as an athlete and foreseeing future life roles are the part of self-exploration interventions in career assistance programs for decades. If P knew about the notion of life roles in advance, the way of looking at her current situation might be differed.

"That's why, there is no challenge at all anymore. This is, well, I think it can't be helped. Yes. But, if you give up something, it will not continue, so I will continue." $\mathrm{P}$ felt that the current situation is not challenging using her own definition of "challenge" based on her experience as an athlete. In addition, A regards the post-retirement world as a world in which it is not necessary to live a challenging life by looking around at 
others. Besides, P regards the current world as a world where she had to care about the

balance in living. From this, it seems that $\mathrm{P}$ accepted the current situation as being

unavoidable. Although $\mathrm{P}$ is dissatisfied with the fact that it is not challenging, she thinks that

if she gave up and quit, it would be the real end. So, she made the choice to continue.

"In the past, you would have to put out $120 \%$ of the power. Otherwise you didn't feel you were working hard enough. It's not like that now. The environment I have now, the environment given to me now, I just do what you can in the given environment. This, doing what you can do, is like only 30 or $40 \%$ of my effort comparing to the past. So, that kind of myself, is it OK like this? I just think, I want to do more, burning heart. You know we have the kind of DNA, don't you? I am trying to make it good, adjust it myself. Balancing is needed for me now.

For P, the definition of "work hard" based on her athletic experience was to exert $120 \%$ of her power. However, now it is important not to use it as her standard, but to do things as much as possible in the current environment. At the same time, since this standard which cultivated in the athletic life was deeply rooted in $\mathrm{P}$, she feels that this was as much as $30 \%$ comparing to the old days. Therefore, $\mathrm{P}$ sometimes desires to do more in this present situation, and she is using the word DNA to describe herself. This is considered to be the recognition that $\mathrm{P}$ thought that she had a characteristic of athletes. Also, from the expression "don't you?", the reference to "the model story of an athlete who lives in the Synchro world" was observed here, and it can be said that the interviewer recognized the person as having the same DNA. And from the statement "balance is necessary for me now", it can be seen that she recognized that putting $120 \%$ of the power according to the athlete's DNA would be overkill in her current life.

"I think being an athlete was definitely more stressed than now if I think about it now. But, at that time, we did to the end, right? We did 100\%. But now, I have stress that I can't do with 100\%. I have the stress that I couldn't do until the limit. It means that I can't push myself hard. In my mind, I don't have time. You know I want to do up to this much, but I have to pick up kids. I have this kind of stress. I'd better really not to think this is stress, but I can't help feeling stressed about those things. I guess I feel stressed to be in the half-way."

$\mathrm{P}$ felt that it is more stressful now than the time of being an athlete even though the athletic time must have been really hard. She felt stressed about not being able to do what she 
wanted, such as not working hard and lacking time, comparing the days of working hard to the limit every day as an athlete. And P self-analyzed that being halfway was stressful, and also seemed to understand the value learned from the appearance of others who met after retirement. There is a conflict between herself as an athlete and herself at present.

$\underline{\text { New Values }}$

"It's completely different way of thinking from the way as an athlete. So, it is not winning for myself only. I just realized so many things. When I was an athlete, I was just doing my best. But not that. I am on the top of the people supported me. I am just sitting in the most shining place. I realized in the TV studio that there are so many people supporting me. Sitting on the stage of the studio, you see, there are many kinds of people in the studio. There are sub directors, sceneshifters, and others. I can see them right in front of me. Wow, there are so many people supporting the TV show. Then, I noticed that maybe Synchro was the same. I noticed now. It's been so long since I retired. How silly I was when I was an athlete. I was not thinking about anything."

$\mathrm{P}$ strongly recognized the difference in the way of thinking from the time of being an athlete. Through her work on television, she learned that she could shine in a good position only with the support of many people. Through this awareness, P realized that she was the same when she was doing Synchro. At that time, she was thinking about herself only that she did not notice the support of people.

"But I was saying thank you very much in word. I said it, but what did I really appreciate? I just realized that. I felt that the only thing I could see in front of me was the coach."

$\mathrm{P}$ used to say thank you during her athletic career, but began to realize that it might

have been superficial. P remorsefully reconsidered that she cared about her coach only so that

she couldn't see many people who supported her, and she could not be truly grateful.

Looking back on herself as an athlete, $\mathrm{P}$ realized that the quality of gratitude was different than it is now.

"For me, I tried a lot of challenging things, and even Cirque, I did what I wanted to do. I've lived long time thinking that I can't understand unless I try. But, I realized that there are people who can't do like this. I realized that it was strange to impose my thoughts on people." 
lot of time with coaches and teammates who had the same goal of winning medals at the

486

487

Olympics. So that she assumed that her thoughts were correct. However, after retired, P met many people and found that not all of them lived the same way as she did. Then, P seems to have begun to realize the meaninglessness of evaluating others based on her own criteria as an athlete and imposing her own thoughts.

"If I make it simple, it's just not about winning. Winning, I've always thought that I won't be recognized unless I win, but, I think the world is like that. But it's not all that you are recognized by people. We are not living for getting people to recognize you. I would be happy to get recognized, and I'm happy if I'm praised or told me that I'm amazing. But it's not all that. Not only that sense of value, but what you are is actually the most important thing."

Since P lived in the world of judging sport where rankings were decided by judges, it seems that she had a strong feeling of being recognized otherwise she would not be able to win. However, after retired, she began to think not only about winning and losing, but also about her own way of life. At the same time, P thought that the desire for approval was also a natural desire for humans. It is considered that A has come to accept herself having the desire of being recognized.

"After retired, I went to the media world. Of course, if I did something wrong on TV and people hate about, then I can't stay there. But, I'm not working to be liked by all millions of people, so, like myself, who I am, I can live a little more naturally and it's $O K$ to be relaxed in life."

Being involved in the media business, $\mathrm{P}$ realized that she wasn't working to be liked

by everyone. As a result, she encountered a new way of life in which she could live naturally and relaxed.

"Gradually, I started to notice various things little by little. Well, well, I was at the top in Synchro, but the level of commentating is less than zero. For example, I was swimming all the time when all ordinary students were studying for 4 years. My starting line is really behind comparing to others. It is obvious that the level or my start line is behind. After all, I wonder what this is for various people. I was starting to wonder if it's okay to expose myself a little more. It was the second or third year of starting the job." 
517 she could not do well because the challenges changed. Then, she began to accept herself that

518 it was OK to be behind comparing to others because she was an athlete for a long time. By

519 admitting not being able to do things well, she was able to correctly evaluate what she could

520 do at the same time. It seems that this led to the courage to expose herself to others.

\section{$521 \quad \underline{\text { Transferable Skills }}$}

522

523

524

525

526

527

528

529

530

531

532

533

534

535

536

537

"To get results, enough preparation is needed mentally and physically, it's easy to say, but I was able to really experience it. That fits to anything. In anything, preparation and process are important. There is no unfounded confidence. It's similar to the one I talked about earlier, but I'm having a well-founded confidence only in me. You just need to prepare. At least the minimum preparation. At work as well. And preparing for kids are the same. All needs preparation. I need to prepare for the time comes. That was something very important as an athlete."

Transferable skills are defined as skills learned in one area of life that can be used in another area (Murphy, 1995). Athletic transferable skills can be defined as abstract skills learned in the athletic environment that are applicable to another career (Mayocchi \& Hanrahan, 2000). P was experiencing how much mental and physical preparation was needed to produce results. P seems to have learned about the necessary approach to produce results no matter what the issues are. This kind of preparation are thought to be come from her will to succeed. The will to succeed is one of the transferrable skills among elite athletes (Mayocchi \& Hanrahan, 2000). It is assumed that P didn't know the notion of the transferrable skills but she knows she learned these through her athletic life and that they are still useful in her present life.

"I had to be sharp otherwise I can't reach the top. So that if you do loose thing, you can't become a number one in the world. I used to be very, very sharp. I think that having such an experience when I was young was an extremely valuable asset. I can't live like this for the rest of my life. But after all, being able to experience such a thing when I was young, once you become an adult, you can't do easily, don't you think?" $\mathrm{P}$ thought that it was important not to be loose and to be in a sharp state in order to aim for the top in the world in a certain field. And the experience was difficult to get even if 
one tried to experience it after becoming an adult. That is why she regarded her experience of

547 being able to do it when she was young as a valuable asset. Also, from the expression "don't

548 you think?", "a model story of an athlete living in the Synchro world" was observed here as

549 well, and P recognized the interviewer as the same experienced person who experienced a

550 sharp state in her youth. P thought having the experience of being sharp was valuable even though P thinks that this sharp state is not needed in the world after retirement. If the sharp experience can be interpreted as achievement feeling, then it can be thought as a transferable skill (Petitpas et al., 1992).

This can be interpreted in several transferable skills. If "knowing how to make an effort to get results" can be defined transferable skills such as the ability to attain goals, perseverance, and self-motivated (Mayocchi \& Hanrahan, 2000). P was involved in the sport since she was a child and thought that this continuous experience was important. Also, she thought that doing competitive sports and taking on challenges would experience negative results that did not go as expected. However, P believed that if she continued to make efforts, something new would

be born, and she believed that continuous experience would become her career.

"There is a word, having a successful experience. But for us, we experience both success and failure through sports, right? Because I experienced all of these totally, I know if I do something, I would either succeed or fail. But I know someday success would come. After all, if you do not challenge first, nothing will start. I think that the experience value that I am experiencing in sports is being utilized to the fullest in my subsequent life."

$\mathrm{P}$ knows empirically that the person who had a successful experience knew both 
578 Hanrahan, 2000). It can be seen that $\mathrm{P}$ felt that the experience gained through sports were asking the interviewer to understand. This kind of narrative can be considered that $\mathrm{P}$ recognized the interviewer understood the model story, which was observed as being referred to the "model story of an athlete who lives in the Synchro world." It can be seen that P felt that the experience gained through sports were still useful in life after retirement.

Advice for the Next Generation

themselves. From the expression "don't you think?", the reference to "the model story of an athlete who lives in the Synchro world" was also observed here, and the interviewer was to be recognized as the same awareness as herself. However, if the awareness of the problem through the athletic experience remains too sensuous, it would be difficult to convey it to that purpose, and $\mathrm{P}$ asked agreement to the interviewer "don't you think?" that $\mathrm{P}$ still feels

that there was a trend of it is $\mathrm{OK}$ to do only sports without studying during the athletic career. directed without noticing that I was directed. I was on the decided rails. It was not the rails I chose. I was running on the rails and I was pushed from behind. So, instead of being pushed on the rail from behind, after all, you have to choose your own way to go, you have to hold your own rudder, you have to have your driving force, you have to go forward by yourself. Otherwise, if you don't do that, you'll regret it somewhere, and myself, I think there are various regrets about this. When I was an athlete. That's 
why I was able to do that, you know that is why I was able to win a medal. I know that is why I am here. But well, you know. Even when you are as a second career, if you stumble again, well I am sure you stumble. Even if you take a detour, you should go on your own."

$\mathrm{P}$ thought she was running on her own rails but realized that she was actually running on a rail without her will. It is assumed that the rails were decided by her coach. And because of that, $\mathrm{P}$ believed that she was able to win the medal. At the same time, she admitted that she had regrets. Because $\mathrm{P}$ believed that her regrets led to a stumbling block in the second career, she appealed for the need to go on one's own, even if one makes a detour. P emphasized that what is needed immediately after retirement is learning and autonomy. In other words, looking back now, it can be inferred that $\mathrm{P}$ herself wanted to learn and become autonomy at retirement.

From the P's life story, several important results are observed. First, development of her athletic identity was found. She committed herself in her sport and developed her athletic identity around the age of junior high school, and her self-image was developed relating to her sport such as "swimming machine" and "zero or 100". Second, the Olympic self-image caused difficulties at retirement. Third, starting new career needed some coping strategies with her transferable skills. And lastly, psychological difficulties relating to athletic identity still existed even after more than decades from her retirement.

At the end of the analysis of the P's life story, the followings also should be noted. P achieved her athletic goal by receiving two Olympic medals and three world championships medals. After the successful results, $\mathrm{P}$ was known as retired for psychological reasons. Since the sporting goal achievement was positively related to post-sport life satisfaction among retired athletes (Sinclair \& Orlick, 1993), P would be thought satisfied with her post-sport life. $\mathrm{P}$ didn't mention about the degree of satisfaction in her life; however, $\mathrm{P}$ told the interviewer/author that she still didn't want to confront about the real causes of her retirement. In other words, P revealed in the interview that she did have a different cause of 
the retirement from what she used to say in public. Although P didn't have a clinical psychological issue during and after her retirement, it is assumed that $\mathrm{P}$ had some psychological adjustment difficulties even now. P has managed by herself using various

640 coping strategies in her own way, but it is presumed that there is still a conflict between

641 herself as an athlete and her present self even after nearly 30 years of her retirement. Athletic

642 retirement research so far has clarified the needs for interventions at the time of retirement

643 and the needs for proactive interventions before the retirement. From P's case, it is observed

644 that a former elite athlete who retired for several decades still has psychological difficulties

645 including an athletic identity issue. It is assured that a psychological intervention for athletic 646 retirement is needed in Japan.

\section{Conclusion}

The purpose of this study was to further advance research in the area of retirement

649 from sport, with a specific focus the developmental experiences related to the sport career

650 transition process in Japan. The findings add detail to Lavallee et al.'s (2012) conceptual

651 model of retirement from sport. Specifically, the result of the study revealed that the

652 developmental experiences during the athletic career affected the athlete's identity formation

653 and loss of self-confidence (Lavallee et al., 2014). For the psychological adjustment

654 difficulties related to athletic identity at retirement, helping athletes develop a sense of who

655 they are beyond sport is a useful intervention that can occur anytime in an athlete's career

656 (Lavallee \& Anderson, 2000). It would be better to get consulted by a sport psychology

657 professional prior to the retirement as a proactive coping strategy; however, once athletes

658 retire, a psychological approach by professionals is needed to help athletes developing an

659 understanding of what they are going through in the transition (Baillie, 1993; Petitpas et al., 660 1996). 
662 and Ryba (2013) have highlighted how further research on cultural differences is required.

663 Moreover, a recent paper by Taku and Arai (2020) highlighted the importance of research in

664 Japan given the postponement of the 2020 Tokyo Olympic and Paralympic Games as a result

665 of COVID-19. The results of this research, therefore, advance knowledge in this area in

666 Japan. However, the present study cannot generalize Japanese athletes' psychological

667 difficulties at their retirement. Based on the findings presented in the current study, combined

668 with the previous research by Oulevey et al. (2018) and Oulevey et al. (2020), we recommend

669 further research to help progress towards the development of a psychological support system

670 to help retiring athletes make an optimal career transition. 
athletes. Psychology of sport and exercise, 5(1), 61-75.

Baillie, P. H. (1993). Understanding retirement from sports: Therapeutic ideas for helping athletes in transition. The Counseling Psychologist, 21(3), 399-410. human behavior. New York: Plenum. guide. California: Impact Publishers.

Hong, H. J. \& Coffee, P. (2018). A psycho-educational curriculum for sport career

Lavallee, D. \& Andersen, M. B. (2000). Leaving sport: Easing career transitions. In

Mayocchi, L. \& Hanrahan, S. J., (2000). Transferable skills for career change. In D. 
699 Olympians' causes of career termination depending on the differences between

700 Summer/Winter and male/female. Journal of Japan Society of Sports Industry, 28(4), 295306. strategies to athletic retirement stressors among Japanese female athletes. Paper presented at International conference on psychology, Tokyo, Japan. systematic review. International Review of Sport and Exercise Psychology, 6, 22-53. program for elite athletes. Journal of Counseling \& Development, 70(3), 383-386. athlete: Theoretical, empirical, and practical perspectives. Counseling college studentathletes: Issues and interventions, 2, 137-156.

Guide to Career Planning. Champaign, IL: Human Kinetics. sport career transition programs. D., Lavallee, P. Wylleman, (Eds.), Career transitions in sport: International perspectives, 81-93. intrinsic motivation, social development, and well-being. American Psychologist. 55, 68-78. 
Sakurai, A. (2002). Intabyū no shakai-gaku — raifusutōrī no kikikata [Sociology of

721 the Interview: How to Listen to Life Stories]. Serika Shobō, Tokyo.

722

Sinclair, D. A., \& Orlick, T. (1993). Positive transitions from high-performance sport. The sport psychologist, 7(2), 138-150.

Stambulova, N. B., \& Ryba, T. V. (2013). Setting the bar: Towards cultural praxis of athletes' careers. In N. Stambulova \& T. V. Ryba (Eds.) Athletes' careers across cultures (pp. 235-254). London: Routledge.

Taku, K., \& Arai, H. (2020). Impact of COVID-19 on athletes and coaches, and their values in Japan: Repercussions of postponing the Tokyo 2020 Olympic and Paralympic Games. Journal of Loss and Trauma, 25, 623-630. DOI: 10.1080/15325024.2020.1777762

731 Jiga douitsu sei no saitaisei-ka o megutte [A Study on athletic retirement of elite athletes:

732 From the viewpoint of restructure of self-identity]. Japanese Journal of Physical Education, 733 Health and Sport Science, 41, 192-206. Uphill, M. \& Jones, M. (2012). The consequences and control of emotions in elite

735 athletes. In Thatcher, J., Jones, M., \& Lavallee, D. (Eds.), Coping and emotion in sport (2 ${ }^{\text {nd }}$ 736 ed., pp. 33-61). London: Routledge. 